\title{
CORRECTION
}



Cite this: J. Mater. Chem. B, 2017 5,181

DOI: 10.1039/c6tb90173e

www.rsc.org/MaterialsB
View Article Online

View Journal | View Issue

\section{Correction: Reversible PEGylation and Schiff-base linked imidazole modification of polylysine for high-performance gene delivery}

\author{
Xiaojun Cai, ${ }^{\text {ab }}$ Yongyong $\mathrm{Li}{ }^{\mathrm{b}}$ Dong Yue, ${ }^{\mathrm{a}}$ Qiangying $\mathrm{Yi}^{\mathrm{a}}{ }^{\text {S Shuo } \mathrm{Li}{ }^{* \mathrm{ac}} \text { Donglu Shi }}{ }^{\mathrm{b}}$ \\ and Zhongwei Gu*a
}

Correction for 'Reversible PEGylation and Schiff-base linked imidazole modification of polylysine for high-performance gene delivery' by Xiaojun Cai et al., J. Mater. Chem. B, 2015, 3, 1507-1517.

The authors regret that one of the author names, Zhongwei Gu, was spelled incorrectly as Zhongwu Gu. In addition, the email address zwgu@scu.edu.cn was given incorrectly as zwgu@scu.eud.cn. The corrected list of authors and contact details for this article are shown here.

The Royal Society of Chemistry apologises for these errors and any consequent inconvenience to authors and readers.

\footnotetext{
${ }^{a}$ National Engineering Research Center for Biomaterials, Sichuan University, Chengdu 610064, China. E-mail: zwgu@scu.edu.cn; Fax: +8628 85410653; Tel: +862885412923

${ }^{b}$ The Institute for Biomedical Engineering and Nano Science, Tongji University School of Medicine, Tongji University, Shanghai, 200120, China. E-mail: yongyong_li@tongji.edu.cn; Fax: +8621 65983706; Tel: +86 2165983706

${ }^{c}$ School of Chemical Engineering, Chongqing University of Technology, Chongqing 400054, China
} 